\title{
Comercialización de cueros de pecarí Tayassuidae en la provincia de Salta, Argentina y evaluación de su política de conservación. Período 1973-2012
}

\author{
Peccari Tayassuidae skin trade in Salta Province, Argentina and \\ evaluation of its conservation policy. Period 1973-2012
}

\author{
Francisco Ramón-Barbarán*
}

\begin{abstract}
Resumen
Considerando la importancia geopolítica de la provincia de Salta, ubicada en el límite de Argentina con Bolivia y Paraguay. Objetivo: Analizar la coherencia entre el comercio, la legislación y la administración de Pecari tajacu y Tayassu pecari teniendo en cuenta la dinámica del comercio de cueros con provincias y países vecinos. Métodos: Se revisaron archivos de la agencia provincial de fauna y se entrevistaron a informantes calificados. Las exportaciones de Argentina, se analizaron sobre la base de certificados CITES entre 1980 y 2004 cuando finalizaron. Resultados: Salta comercializó legalmente 46.111 cueros en el período 1973-1977 y 12.600 entre 1988 y 1992. Actualmente solo se permite en Salta la caza deportiva, el uso comercial de estas especies continúa abasteciendo principalmente al mercado interno. La obtención de carne es el principal motivo de la cacería. El sistema administrativo del comercio de los cueros tiende a legitimar el tráfico ilegal, al existir contradicciones entre la legislación de las provincias y el sistema de acreditación de existencias para los comerciantes, que les permitió continuar en el mercado internacional 16 años después que las exportaciones fueron prohibidas en 1988. Durante el período 1980-2000 se exportaron 561.158 cueros de $P$. tajacu y distintos países registraron la importación de 36.173 cueros de T. pecarí con origen en Argentina Conclusiones: La implementación de sistemas de producción multiespecíficos, sería una alternativa para el uso sostenible de los pecaríes.
\end{abstract}

Palabras clave: Pecari, Uso sostenible.

\begin{abstract}
Considering the geopolitical importance of the Province of Salta, located on the border of Argentina with Bolivia and Paraguay.Objective: To analyze the coherence between the commerce, legislation and administration of (Pecari tajacu) and (Tayassu pecari) Account the dynamics of the trade of leather with provinces and neighboring countries. Methods: The files of the provincial wildlife agency were checked and key informants were interviewed. The Argentinean exports of peccaries were analyzed during the period 1980-2013, using the CITES trade database. Results: In Salta, 46111 hides were legally traded between 1973 and 1997 and 12600 during the period 1988-1992. Although sport hunting of peccaries is legal in Salta, the trade continue supplying the internal skin market. Now a day, to obtain the meat is the main reason for trapping. Conclusions: The administrative systems are inefficient and trend to increase the illegal trade, due to contradictions between the legislation and the stock documentation system for traders. That system allowed them to continue in the international market, even 16 years after the exports were banned in 1988 by Argentina's CITES Administrative Authority. During the period 1980-2000, 561.156 skins of ( $P$. tajacu) were exported, while 36.173 skins of ( $T$. pecari) with origin in Argentina, were imported by different countries. The implementation of multispecific production systems, may be an alternative for the sustainable use of the peccaries.
\end{abstract}

Keywords: Peccary, Sustainable use.

* Investigador Adjunto, Consejo Nacional de Investigaciones Científicas y Técnicas, Salta, Argentina. e-mail: frbarbaran@yahoo.com.ar Fecha recepción: Marzo 30, 2017 Fecha aprobación: Mayo 17, 2017 Editor Asociado: Neita-Moreno J

(C) Rev. Biodivers. Neotrop. 2017; 7 (3): 169-88 


\section{Introducción}

La provincia de Salta, con una extensión de $155.368 \mathrm{~km}^{2}$, está ubicada en el norte de la República Argentina $\left(22^{\circ} 26^{\prime} \mathrm{S} 62^{\circ} 66^{\prime} \mathrm{W}\right)$, limita con las provincias de Jujuy, Catamarca, Tucumán, Santiago del Estero, Chaco y Formosa.

El pecarí de collar o rosillo (Pecari tajacu) y el pecarí labiado o majano (Tayassu pecari) especies de hábitos gregarios, se encuentran entre el este y centro de Salta, en los ecosistemas correspondientes a la Selva Tucumano Boliviana y Chaco Occidental, también llamado Chaco Semiárido (Redford y Eisemberg 1992). En esta última región también se encuentra el "quimilero" (Catagonus wagneri) que es la especie menos representativa de los pecaríes, también conocidos en Salta como "chanchos del monte". El rosillo y el majano a través de su amplia área de distribución (desde el sur de los Estados Unidos hasta el norte de Argentina) (Robinson y Redford 1991a) tienen alto valor como recurso alimenticio, siendo en este sentido las especies más importantes del Neotrópico.

El retroceso del hábitat por sobrepastoreo, tala irracional de árboles con valor comercial, desmontes para la expansión de la frontera agropecuaria y el comercio de cueros son los principales problemas que afectan a estas especies y han sido escasamente estudiados en Argentina (Bucher 1980, 1989, CITES 1999, Fuyita y Calvo 1982, Gruss 1991, Gruss y Wa1ler 1988, Hemley 1986, Ojeda y Mares 1984, Mares y Ojeda 1984, Richard 1992, Saravia-Toledo 1989a, 1989b, 1995, Saravia-Toledo y Barbarán 2003). Sin embargo, es importante el volumen de producción científica sobre los pecaríes en otros países (Bodmer et al. 1993, 1997, Broad 1984, Glanz 1991, Hvidberg-Hansen $1973^{1}$, Richard 1992, Robinson y Redford 1991a, 1991b, 1991c, Sowls 1984, Taber 1990a, 1991, Taber et al. 1993, 1994, Vickers 1991).

Partiendo del trabajo sobre comercio de pecaríes, (Barbarán 1999) entre 1973 y 1997, se actualizó la información comercial entre 1997 y 2013, teniendo en cuenta que Salta, por su posición geopolítica, es puerta de entrada de productos de la fauna con origen en Bolivia y Paraguay, como también de provincias vecinas. Se plantea el objetivo de analizar desde una perspectiva histórica y actual el comercio de cueros de pecarí (P. tajacu y T. pecari), la legislación sobre fauna silvestre y la administración del recurso, teniendo en cuenta la dinámica del comercio con provincias y países vecinos. En relación con lo anterior, se hace referencia a la condición del hábitat y al efecto de la cacería sobre estas especies.

\section{Metodología}

El método para analizar el comercio y administración del recurso, se basa en el entrecruzamiento de información proveniente de distintas fuentes. De esta forma se confeccionó una base de datos con estadísticas de comercialización, de acuerdo con las guías de tránsito (documento necesario para el transporte interprovincial de los cueros) emitidas entre 1973 y 1992 por la agencia provincial de fauna silvestre, Secretaría de Medio Ambiente y Desarrollo Sustentable de la Provincia de Salta (SMADS). Todo el archivo de la SMADS fue relevado, con el fin de acceder a informes internos sobre el comercio de cueros y pieles, registros de decomiso por comercio ilegal y políticas de administración de la fauna silvestre.

También, se recabó información en Buenos Aires sobre legislación y exportaciones de pecaríes ante la Autoridad Administrativa CITES (Convención Internacional para el Comercio de Especies Amenazadas) de Argentina, que se denomina actualmente Secretaría de Desarrollo Sustentable y Política Ambiental (SDSPA). Igualmente fue consultada la base de datos sobre el comercio de cueros de pecaríes en el período 1980-2016 confeccionada por el World Conservation Monitoring Centre (WCMC) sobre la base de reportes de certificados CITES de Argentina, Bolivia, Brasil, Paraguay y Perú, e información comercial proporcionada por las Autoridades Administrativas CITES de Paraguay y Perú.

Área de estudio. Se tomó como área de estudio al Chaco Semiárido. El paisaje chaqueño original, consistía en un parque natural donde alternaban bosques con pastizales, manteniéndose este mosaico de vegetación gracias a incendios provocados por rayos o intencionalmente por los indios, en una suerte de equilibrio pulsátil (Morello y Saravia Toledo 1959a).

Hvidberg-Hansen H. 1973. Utilización de pieles de los animales silvestres en la selva del Perú. Lima: Universidad Nacional Agraria "La Molina"; 23 pp. (Inédito). 
Después de la colonización europea, la frecuencia de los incendios disminuyó a medida que los indios se retiraron y el ganado consumió los pastizales, combustible necesario para los incendios. Esto provocó la rápida colonización de los parches de pasto por vegetación leñosa, a un punto tal, que desaparecieron casi completamente (Saravia Toledo 1995, Saravia Toledo y del Castillo 1988).

La cobertura y alimentación de la fauna es afectada directamente por la ganadería practicada sin ningún orden (Morello y Saravia Toledo 1959a), ya que el ganado también consume árboles y arbustos forrajeros que ven impedida su regeneración por el sobrepastoreo, lo que produce extensos peladares (Figura 1).

Se realizaron doce viajes de campaña, visitando los departamentos de Anta $24^{\circ} 47^{\prime}$ S $64^{\circ} 14^{\prime}$ W, San Martín 22 $30^{\circ} 45^{\prime \prime} \mathrm{S} 63^{\circ} 45^{\prime} 09^{\prime \prime} \mathrm{W}$ y Rivadavia $24^{\circ} 11^{\prime} \mathrm{S}$ $62^{\circ} 54^{\prime} \mathrm{W}$ (concentrando la tarea en este último) re-

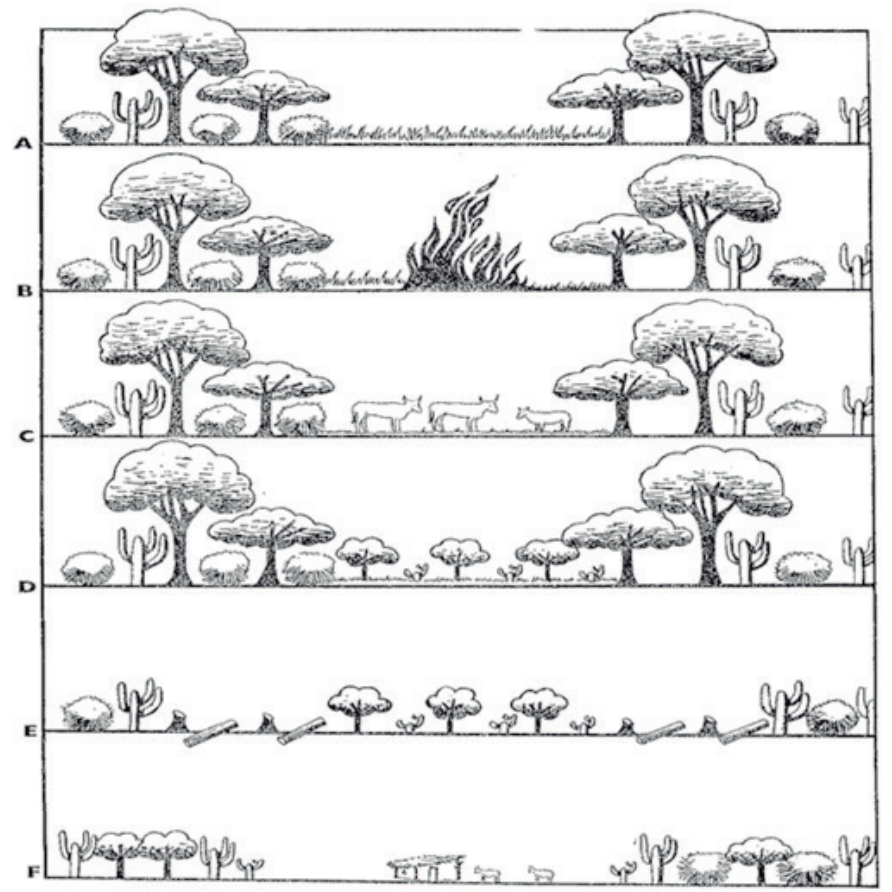

Figura 1. Ganadería a campo abierto consume el combustible provisto por el pastizal (C), que es colonizado por vegetación leñosa (D). La explotación forestal irracional y el sobrepastoreo impiden la regeneración de bosques y pastizales (E). El paisaje actual está representado por un arbustal denso e improductivo con predominancia de ganadería de cabras, donde se asienta un puesto rodeado por un anillo de tierra erosionada sin ninguna cobertura vegetal, conocido como "peladar" (F).

Fuente: Bucher y Schofield, 1981 corriendo las localidades de Alto La Sierra $22^{\circ} 44^{\prime} \mathrm{S}$ $62^{\circ} 30^{\prime} \mathrm{W}$, Morillo $23^{\circ} 28^{\prime} \mathrm{S} 62^{\circ} 53^{\prime} \mathrm{W}$, La Unión $23^{\circ} 53^{\prime} \mathrm{S} 63^{\circ} 10^{\prime} \mathrm{W}$, Rivadavia $24^{\circ} 11^{\prime} \mathrm{S} 62^{\circ} 54^{\prime} \mathrm{W}$ y Santa Victoria Este $22^{\circ} 16^{\prime} \mathrm{S} 62^{\circ} 42^{\prime} \mathrm{W}$, las que fueron tomadas como puntos de acopio. Los acopiadores identificaron 37 parajes como sitios de caza, los que se visitaron para realizar 115 entrevistas semiestructuradas a cazadores (Figura 2).

En los puntos de acopio se hicieron 16 entrevistas semiestructuradas a comerciantes (acopiadores de cueros), quienes se refirieron a precios, calidades y capacidad de acopio; 69 informantes clave también se entrevistaron: científicos vinculados con la especie,
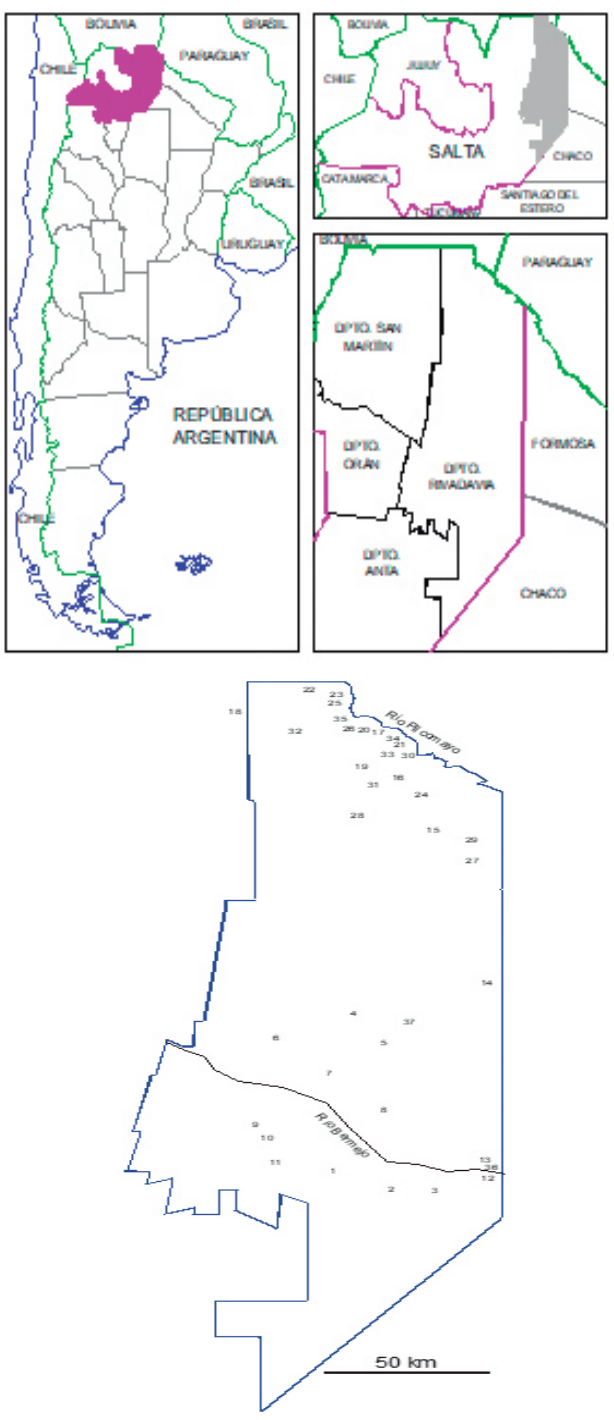

Figura 2. Ubicación aproximada de los pueblos y parajes del departamento Rivadavia donde se entrevistó a cazadores y acopiadores. 
Tabla 1. Entrevistas relacionadas con el comercio y administración de pecaríes en la ciudad de Salta, Buenos Aires y el Chaco Salteño Semiárido. Período 1988-2013

\begin{tabular}{|c|c|}
\hline Categoría & $\mathbf{N}^{\circ}$ de entrevistas \\
\hline Cazadores Wichia & 58 \\
\hline Cazadores Tobas ${ }^{a}$ & 5 \\
\hline Cazadores Chorotes ${ }^{a}$ & 1 \\
\hline Cazadores Chiriguanos $^{a}$ & 5 \\
\hline Cazadores Tapietes $^{a}$ & 4 \\
\hline Cazadores criollos & 55 \\
\hline Acopiadores de distinta importancia & 16 \\
\hline Curtidores locales & 1 \\
\hline Exportadores-curtidores & 6 \\
\hline Empleados de curtiembre & 10 \\
\hline Inspectores de fauna (nivel provincial) & 11 \\
\hline Autoridades de fauna (nivel provincial) & 7 \\
\hline Funcionarios de fauna (nivel nacional) & 3 \\
\hline Investigadores & 5 \\
\hline Informantes calificados ${ }^{b}$ & 26 \\
\hline
\end{tabular}

Fuente: Del autor

a Etnias indígenas presentes en el Departamento Rivadavia, en la Provincia de Salta.

b Los informantes calificados comprenden a encargados de casas de comidas, empleados de estaciones de servicio, maestros, transportistas, miembros de la Policía de Salta y de Gendarmería Nacional.

encargados de casas de comidas, empleados de estaciones de servicio, exportadores y administradores de fauna en los niveles provincial y federal, maestros, miembros de la policía de Salta y de Gendarmería Nacional (policía de frontera de la República Argentina) y transportistas (Tabla 1).

Los datos recogidos en las entrevistas a cazadores, estuvieron referidos a las técnicas de caza de las especies de interés y precios de los cueros. Se tomaron como reales los precios mencionados con mayor frecuencia por los cazadores, que a la vez coincidían con los indicados por los acopiadores y los informantes clave restantes.

Para conocer la condición del hábitat de los pecaríes, se recurrió al relevamiento bibliográfico sobre las actividades económicas más importantes en el área de distribución de estas especies en la provincia de Salta. También se realizaron observaciones sobre el terreno, participando en actividades de caza y coleccionando las plantas que según los cazadores forman parte de la dieta de los pecaríes. Las plantas se coleccionaron e identificaron taxonómicamente, confeccionándose un herbario depositado en la Fundación para el Desarrollo del Chaco. Se consultó a un funcionario de la Dirección de Minería de Salta, sobre el impacto en el hábitat de la actividad petrolera.

\section{Resultados}

Características de la caza de subsistencia. Indios y criollos (pastores con hábitos de caza y recolección) cazan chanchos del monte durante todo el año a través del uso de perros entrenados y armas de fuego, principalmente rifles de calibre 22 y escopetas de preferencia de calibre 28, 16 y 12; también se usan armas de puño, cuchillos dispuestos sobre varas de madera dura a manera de lanzas y garrotes. Lo más importante es contar con perros entrenados, porque no todos los cazadores poseen canes con la habilidad de perseguir pecaríes. Las armas de fuego estuvieron presentes en todos los puestos de cazadores criollos visitados, aunque a veces, debido al uso intenso, presentaban la culata rota, atada con tiras de goma o con problemas mecánicos, lo que seguramente incidió en el éxito de captura.

La técnica de caza consiste en la detección de los pecaríes por parte de los perros, quienes los persiguen hasta su refugio y el cazador les da muerte. Los cazadores criollos siempre van cubiertos con ropa de cuero, para evitar herirse con las espinas de los árboles mientras siguen a los perros. La caza de pecaríes es una de las más difíciles y demandantes en energía, ya que los cazadores deben desplazarse entre siete y veinte kilómetros de sus viviendas para encontrar un sitio de caza, debido a la degradación del bosque. El rosillo (Pecari tajacu) fue la especie predominante en las capturas y el quimilero (Catagonus wagneri) la menos frecuente.

Los indios de la etnia Wichi son cazadores-recolectores, aunque solo dos admitieron poseer armas de fuego. Los cazadores manifestaron que capturaban pecaríes ocasionalmente, lo que se explica en el caso de los indígenas que viven sobre las márgenes de los ríos Bermejo y Pilcomayo, en que el pescado es el componente principal de su dieta y reciben alimentos no perecederos a través de programas de asistencia y desarrollo comunitario promovidos por el Gobierno, distintos credos religiosos e iniciativas filantrópicas (Barbarán 2001). 
El objetivo principal de la captura de pecaríes en el área estudiada, en el caso de los criollos fue la obtención de carne para evitar empobrecerse en ganado y también la recreación durante los fines de semana. Indios Wichi asentados sobre el río Pilcomayo (Misión Santa María) ofrecían carne de pecarí a US\$2 por kilo a visitantes ocasionales (obreros de la construcción) en agosto de 1997. No existe un mercado formal para la carne de pecarí en el área de estudio, aunque es común obtener carne de monte por pedido (Barbarán 1999).

En relación con el comercio de cueros, $80 \%$ de los cazadores entrevistados declararon que casi no había demanda de cueros, y que los acopiadores solo recibían pedidos en poca cantidad para abastecer a pequeños fabricantes de botas de la ciudad de Salta. El resto de los entrevistados, simplemente descartaron el cuero.

No se puede afirmar que existe caza comercial porque el precio era bajo en el área de estudio. Es importante aclarar aquí que los cazadores usualmente declaran que el cuero "no tiene precio" si este no supera los US\$5, lo que es válido para cualquier especie, aun cuando los cueros se obtengan y se vendan por un precio inferior, siendo la cacería en este caso, producto de un hecho fortuito. Consideran que un precio inferior no justifica la caza comercial; esto estaría en relación directa con el valor del jornal en el Chaco Semiárido, que oscilaba entre 5.00 y 10.00 dólares (Barbarán 2011).

Registros de acopio de cueros y su relación con la densidad poblacional. De acuerdo con los registros de guías de tránsito de la SMADS, dos acopiadores basados en Rivadavia, comercializaron 38.311 cueros de pecaríes entre 1973 y 1976. En 1975 se guiaron irregularmente desde Salta 4.800 cueros con origen en la provincia de Santiago del Estero. En 1977 se guiaron 3.000 cueros desde Salta, aunque el registro no especifica su origen ni los acopiadores involucrados (Provincia de Salta 1988a). Durante 1988, 1989 y 1992, una curtiembre instalada en Pichanal registró el comercio de 12.600 cueros.

Según los archivos de la SMADS, entre 1973 y 1994 existían registrados 38 acopiadores de cueros y pieles de fauna silvestre que trabajaban en distintas localidades de la provincia de Salta, ubicadas dentro del área de distribución de las especies estudiadas: Dragones: 1; Embarcación: 3; Hickmann: 1; La Unión:
2; Los Blancos: 3; Morillo: 4; Orán: 2; Pichanal: 3; Pocitos: 1; Pluma de Pato: 2; Rosario de la Frontera: 1; Rivadavia: 5; Salta: 5; Tartagal: 4; sin domicilio registrado: 2. Posiblemente, estos comerciantes acopiaban cueros de pecaríes, al coincidir su ubicación con el área de distribución de estas especies.

Aun cuando el comercio de cueros de pecarí está prohibido en la provincia de Salta desde 1992, durante las campañas realizadas entre 1996 y 1999, se detectaron acopiadores activos en: Alto La Sierra: 1; La Unión: 4; Morillo: 4, Rivadavia: 4 y Santa Victoria Este: 2. También se registró la actividad de un acopiador de Sauzalito (provincia del Chaco) que compró cueros en Fortín Belgrano II; otro acopiador con origen en la provincia de Formosa realizó operaciones en Morillo.

De acuerdo con Vickers (1991), la cacería potencial de un área es directamente proporcional a la abundancia, debido a que las capturas están en función de las tasas de encuentro, que dependen de la densidad. Uno de los acopiadores entrevistados en 1998 en Santa Victoria Este, segundo en importancia dentro de los 18 comerciantes existentes en el pueblo, declaró que tiene un radio de acopio de 30 $\mathrm{km}$ a la redonda y que puede acopiar hasta 80 cueros por mes si hay demanda, lo que significa una cacería potencial de 960 cueros por año $\left(0,33\right.$ pecaríes $\left./ \mathrm{km}^{2}\right)$. El acopiador entrevistado, indicó que casi todos los cueros se obtienen en Bolivia y Paraguay, debido a la concentración de cazadores sobre la costa del río Pilcomayo, en territorio argentino. En 1975, año con buena información de acopio, se registró en Rivadavia el comercio de 22.446 cueros $\left(0,87\right.$ pecaríes $\left./ \mathrm{km}^{2}\right)$.

Aunque la cacería potencial en 1998 representa apenas $38 \%$ de la que existía en 1975 en Rivadavia, la cosecha en este año estaría sobredimensionada, porque los datos corresponden al pueblo de Rivadavia Banda Sur, que seguramente captó cueros del departamento de Anta, debido a su cercanía con este. Más allá del área de influencia de Santa Victoria Este, los cueros se acopian hacia el SE, en Alto La Sierra. Un acopiador regional basado en la ciudad de Tartagal (Salta), se traslada periódicamente a estas localidades para recoger los cueros reunidos por los acopiadores locales, lo que confirma el circuito comercial.

Comercio y administración. Salta participa en el comercio de cueros de pecaríes, a través de barracas de acopio de cueros. Sin embargo, la organización 
institucional del comercio de pieles y cueros en Salta ocurre en 1951, al crearse en el seno de la Cámara de Comercio e Industria de Salta, la Cámara Gremial de Barracas y Curtidurías, cuyas actividades finalizaron en 1972 (Cámara de Comercio e Industria de Salta 1951, 1972). Se agrupaban aquí barraqueros acopiadores y exportadores, consignatarios, propietarios de saladeros de cueros y curtidores.

Al constituirse esta Cámara existían 18 socios con actividades en: Metán y Tartagal: 3, Rosario de la Frontera, El Quebrachal y General Güemes: 2, y uno en Joaquín V. González, Lumbreras, La Viña, San Carlos, Embarcación y Capital de la Provincia de Tucumán. En 1965 la Cámara tenía solo 5 socios, todos de la ciudad de Salta, quienes concentraban una porción importante de los cueros y pieles que se producían en la provincia y tenían relaciones con consignatarios y barracas exportadoras, mayoritariamente agrupados en la Cámara Gremial de Comerciantes en Frutos del País, con sede en Avellaneda (provincia de Buenos Aires).

La tipificación de la mercadería se hacía de acuerdo con las pautas establecidas por la Cámara de Subproductos Ganaderos de la Bolsa de Comercio de Buenos Aires, para lo que existía un manual de referencia: "Estilos de Plaza y Embarque que Rigen el Comercio Doméstico". La última edición a la que se tuvo acceso fue la décima (1966) la que seguía siendo consultada en 1989 por los tres barraqueros que trabajaban en la ciudad de Salta.

La tipificación establecía dos clases de cueros de pecaríes: "grises" y "negros" correspondiendo a $P$. tajacu y $T$. pecari respectivamente, llamándose "peludos" a los cueros de C. wagneri. En la jerga comercial también se los conoce como "jabalí", pero el cuero de este es de poco interés al carecer del dibujo típico del pecarí.

Los cueros grises se clasificaban según el largo en: grandes: mínimo $0,85 \mathrm{~m}$, medianos: mínimo 0,70 $\mathrm{m}$, cuartos: mínimo $0,60 \mathrm{~m}$ y pichones: menos de $0,60 \mathrm{~m}$. Los cueros negros se clasificaban en grandes: mínimo $1 \mathrm{~m}$, medianos: mínimo $0,80 \mathrm{~m}$, cuartos: mínimo $0,70 \mathrm{~m}$ y pichones: menos de $0.70 \mathrm{~m}$. Los lotes se negociaban generalmente con $80 \%$ de grandes y $20 \%$ entre desechos grandes y medianos buenos; los cuartos y pichones se negociaban por separado. De acuerdo con el boletín de la Cámara Mercantil de Avellaneda (1983) la diferencia entre grises negros y peludos se mantenía; García Fernández indica la vigencia del sistema en $1991^{2}$.

Durante las entrevistas, un cazador expresó que existen dos calidades según el largo del cuero para el rosillo, porque el majano es muy escaso en la zona: la primera calidad se otorga a los cueros de $1 \mathrm{~m} \mathrm{y}$ segunda calidad para los cueros de $0.70 \mathrm{~m}$ como mínimo, indicando que el cuero de segunda vale la mitad que el de primera.

Por lo general, el acopiador compra al barrer, es decir, hace una oferta global por el lote de cueros que le presenta el cazador; se aclara que los lotes pueden estar constituidos por cueros y pieles de varias especies comunes en el Chaco Semiárido como es el caso de los gatos (Felis sp.) y los zorros (Dusycion sp.). Esta modalidad de comerciar, implica un perjuicio para el cazador, porque tiende a recibir precios inferiores a los reales, y además no se le aplica el sistema de clasificación usado por las barracas de Buenos Aires cuando comercian con acopiadores regionales.

\section{Circuito de comercialización}

Cazador: Indio o criollo (pastor hispano-indígena) que vive en una economía de subsistencia. Cambian los cueros por mercadería, dinero o ambos, aunque el trueque adquiere mayor importancia a medida que se alejan de los centros poblados (Obs. Pers.). Los indios se concentran en comunidades más o menos numerosas, mientras que los criollos viven aislados en puestos ganaderos separados entre sí por distancias entre 3 y $15 \mathrm{~km}$ (Figura 3).

Acopiador ambulante: Actúa por cuenta propia, abasteciendo a los acopiadores regionales (puede ser un cazador con la posibilidad de comprar los cueros de sus vecinos). Se moviliza en camioneta, carros de tiro e incluso bicicleta, ofreciendo a los cazadores artículos de primera necesidad a cambio de los cueros.

Acopiador local: Es dueño de un comercio de ramos generales al por menor, abastecido generalmente por acopiadores regionales, con quienes mantiene estrechas relaciones comerciales.

García Fernández J 1991. Dossier sobre la importancia económica actual de los productos más habitualmente comercializados de la Fauna Silvestre. Buenos Aires: Dirección Nacional de Fauna Silvestre; 14 pp. (Inédito). 


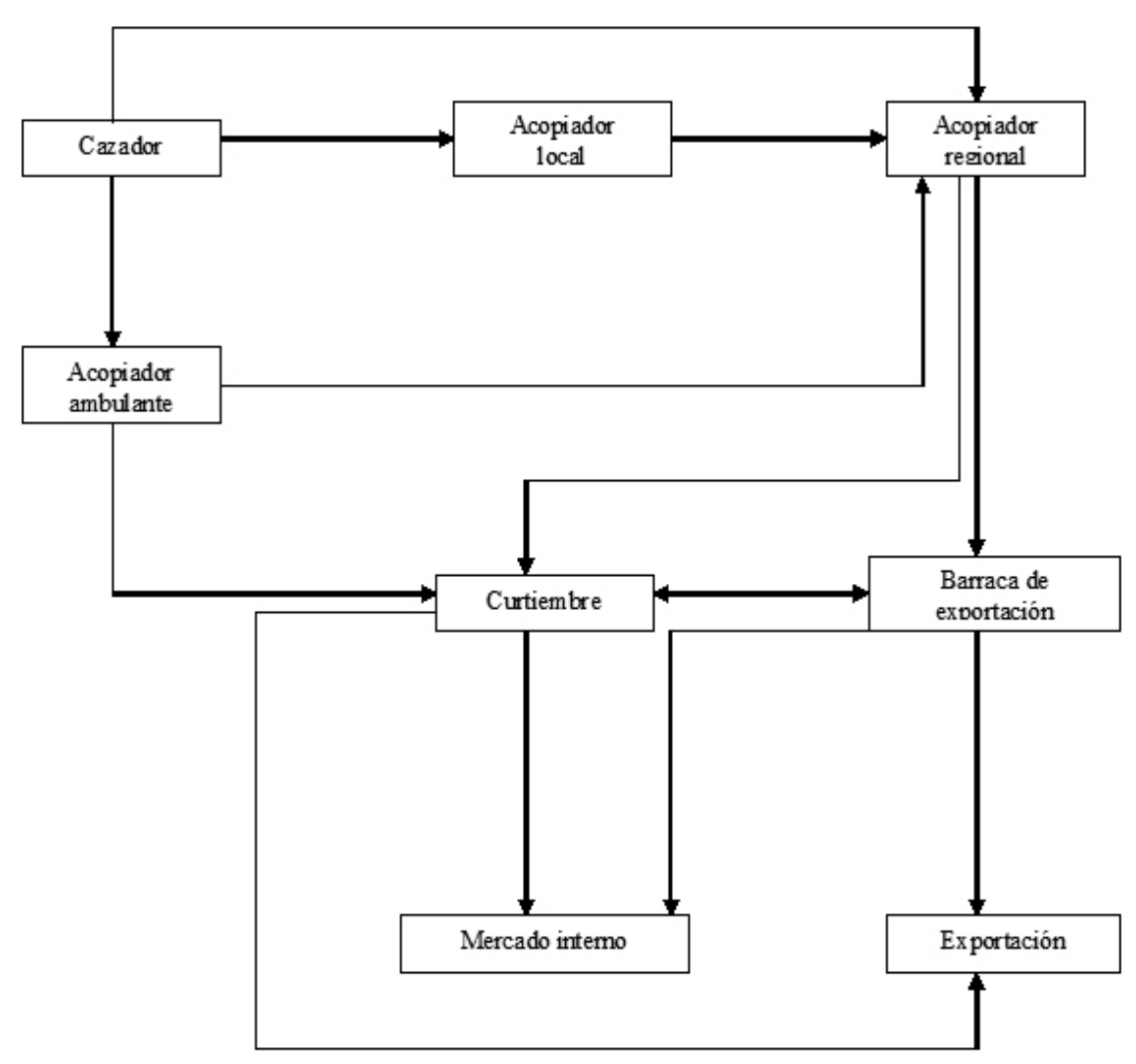

Figura 3. Circuito de comercialización de cueros de pecarí en la Provincia de Salta.

Acopiador regional: Comerciante mayorista ubicado en las localidades más importantes del interior de Salta. Frecuentemente es dueño de tierras y tiene influencias en los gobiernos municipal y provincial, donde suele ocupar cargos públicos en los poderes legislativo y ejecutivo. Generalmente recibe dinero adelantado por parte de los exportadores para comprar los cueros, a lo que suma una diferencia en concepto de comisión. A su vez habilita el crédito hacia los niveles más bajos del circuito comercial.

Barraca de exportación: Los exportadores suelen ser dueños de curtiembres y también pueden abastecerse en grandes barracas concentradoras de cueros de varias provincias en Buenos Aires o en el interior del país. Pueden recibir pagos por adelantado de los importadores quienes se aseguran así del abastecimiento de mercaderías. Esto a su vez habilita el crédito hacia los niveles inferiores de la cadena de comercialización, por lo que es común enviar un corredor a los puntos regionales y terminales de acopio anunciando los precios de la temporada y las especies con valor comercial, adelantando dinero para la compra de cueros.
Curtiembres: En Salta, las curtiembres que comerciaban con cueros de la fauna silvestre, actuaron como barracas de acopio a nivel provincial hasta 1976, año en que se prohibió la exportación de cueros sin curtir por parte del Ministerio de Economía (República Argentina 1976). Esto prácticamente las eliminó del circuito comercial, porque los exportadores se vieron obligados a reducir costos de comercialización, porque debían asumir a su vez los costos de curtido de los cueros para mantenerse en el mercado.

\section{Distribución del ingreso en el circuito comercial}

Entre 1997 y 1998, los cueros de P. tajacu se pagaron al cazador por unidad entre 2.50 y 3 dólares en el punto de origen. En la ciudad de Salta los cueros se pagaron al acopiador 5 dólares. Las curtiembres de Salta (capital) vendían el cuero al menudeo a 45 dólares por $\mathrm{m}^{2}$, lo que involucra dos cueros. Los fabricantes de botas locales las ofrecían al público a 120 dólares y si la venta era a través de zapaterías, a150.00 dólares. Los precios en este último caso, se 
Tabla 2. Precios FOB de Tayasuidos en la República Argentina. Las fuentes no discriminan entre $P$. tajacu y T. pecarí

\begin{tabular}{|c|c|c|}
\hline Año & Precio en dólares americanos por unidad & Fuente \\
\hline 1976 & 2,22 & Fujita y Calvo (1981) \\
\hline 1977 & 7,00 & $" ”$ \\
\hline 1978 & 5,00 & $" ”$ \\
\hline 1979 & 9,68 & $" ”$ \\
\hline 1980 & $6,15-8,62$ & República Argentina (1980) \\
\hline 1981 & 9,73 & República Argentina (1981b) \\
\hline 1982 & 11,59 & República Argentina (1982) \\
\hline 1983 & 4,50 & República Argentina (1983b) \\
\hline 1984 & 3,29 & República Argentina (1984) \\
\hline 1985-1989 & sin datos & 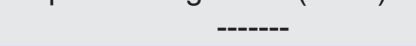 \\
\hline 1990 & $15,00-16,00$ & Bertonatti $\left(1991^{3}\right)$ \\
\hline 1991 & $15,00-16,00$ & García Fernández (1991) \\
\hline 1992-1996 & sin datos & (2) \\
\hline 1997 & 31,15 & Obs. pers., 1997 \\
\hline
\end{tabular}

incrementaron a178.00 dólares en 2013.

Considerando el comercio internacional, a principios de noviembre de 1997 el cuero se ofreció a un precio FOB (Free on Board) de 31,15 dólares por unidad y a 6 dólares por pie ${ }^{2}$, vendiéndose también por $\mathrm{m}^{2}\left(1 \mathrm{~m}^{2}=10.7639\right.$ pies $\left.^{2}\right)$.

García Fernández (1991) indicó que el precio al cazador por cada cuero fue entre 2 y 2.50 dólares; el precio en barracas del interior del país 4 dólares y en barracas de Buenos Aires de 5 y 6 dólares; el valor FOB declarado fue de10 dólares por unidad, estimando el valor real entre15 y 16 dólares (Tabla 2).

En diciembre de 1999, era posible obtener en el comercio minorista de Orán (ciudad del interior de Salta, cercana a la frontera con Bolivia, que sirve como punto de acopio de cueros) un par de alpargatas de cuero de pecari por 7 dólares; en la ciudad de Salta una billetera del mismo material se ofrecía a 33 dólares.

El precio de las alpargatas de pecarí, comparado con el de un par de alpargatas de tela con suela de goma (2.50 y 3 dólares), indica que la demanda es casi nula en los sitios de caza, lo que evidencia que no se estaban acopiando cueros para exportar en ese momento. El costo del curtido también es bajo; de otra forma un producto terminado no podría ofrecerse tan barato, teniendo en cuenta que ya tiene incluido el margen de ganancia del comerciante. En cambio las billeteras ofrecidas en la capital de Salta, estaban dirigidas a un mercado de mayor poder adquisitivo, sobre todo el turístico, siendo el precio casi cinco veces más alto que el de las alpargatas, a pesar de emplear menos materia prima.

Considerando que los cueros de pecarí forman parte habitual de la oferta exportadora de Perú, se cita a efectos comparativos, el precio FOB declarado por los exportadores en este país: 10 dólares por unidad (García com. pers.) en 1997, aunque el precio real fue de 24.50 dólares para el rosillo y 21.22 dólares para el majano. Es interesante observar que en Perú, el precio de los cueros se incrementó constantemente desde 1994 cuando fue de 12.27 dólares para P. tajac y 12.67 dólares para $T$. pecarí.

\section{El comercio de cueros en Argentina y su relación con los países limítrofes}

Aunque Argentina se incorporó a CITES en 1981, el rosillo y el majano fueron incluidos en el Apéndice II de CITES en 1987 (se permite comercio regulado), mientras que el quimilero se ubicó en el Apéndice I (comercio prohibido). Considerando las exportaciones de cueros (P. tajacu) de Argentina y países limítrofes, con base en certificados CITES durante el período 1980-1998 (WCMC 2016) y teniendo en cuenta que Paraguay y Bolivia limitan con la provin- 
cia de Salta, se observa:

\section{P. tajacu}

En Argentina se prohibió la exportación de productos de esta especie en 1987; entre 1988 y 2000 salieron del país 425.305 cueros, casi $70 \%$ de las exportaciones registradas entre 1980 y 2000 . Además, en 1998 se vendieron 600 animales vivos a Japón. Entre 2000 y 2005 se exportaron 260 trofeos de caza. La base de datos CITES no registra movimientos para la especie desde 2006. Ese año, la notificación 006 de CITES indica la prohibición de la exportación de animales vivos, partes y derivados desde Argentina.

Bolivia prohibió todas las exportaciones de fauna silvestre en 1985 manifestando la exportación de dos pares de zapatos en 1986 (Flores s.f.); en 1988 se confiscaron 9.300 cueros. Alemania declaró como precedentes de Bolivia, la importación de 4.200 cueros en 1989 y 6.053 en 1995.

Brasil prohibió el comercio de fauna en 1967 (Ley 5.197), excepto los ejemplares provenientes de criaderos. No informó ninguna exportación de cueros en todo el período estudiado. De acuerdo con los registros del Instituto Brasileño de Medio Ambiente (IBAMA), existían once criaderos de pecarí habilitados en Brasil, de los cuales cinco trabajaban con $P$. tajacu y seis con P. tajacu y T. pecari (Oliveira 19994).

Paraguay prohibió el comercio de toda su fauna silvestre desde 1975 informando la incautación de 7.100 cueros de rosillo en 1988. Sowls (1984) indicó movimiento comercial para las tres especies de pecarí en 1976 y 1979. Taber $\left(1990 b^{5}\right)$ informa que los cazadores recibieron 8 dólares por $P$. tajacu y 5 dólares por T. pecari en 1989 y confirmó el tráfico de cueros hacia Argentina.

\section{T. pecari}

Importaciones con origen en Argentina (36.173 cueros) fueron reportadas por distintos países entre 1988 y 1990.

Bolivia indicó el decomiso de 700 cueros en 1988. La importación de 9.510 cueros es declarada por Italia en 1989 y Alemania informó la importación de 4.551 cueros en 1990.

También resulta interesante comparar el comercio de cueros (P. tajacu) entre Argentina y Perú entre
Tabla 3. Exportaciones de Pecarí tajacu de la República Argentina en cueros por unidad, durante el período 1980-2000. Los datos del período 1985-2000 corresponden a exportaciones netas registradas en la base de datos de CITES

\begin{tabular}{cr}
\hline Año & Exportaciones \\
\hline 1980 & $8.239^{*}$ \\
1981 & $4.900^{*}$ \\
1982 & $7.360^{*}$ \\
1983 & $39.193^{*}$ \\
1984 & $53.574^{*}$ \\
1985 & 8.086 \\
1986 & 0 \\
1987 & 9.000 \\
1988 & 180.448 \\
1989 & 109.260 \\
1990 & 45.534 \\
1991 & 26.912 \\
1992 & 30.864 \\
1993 & 7.878 \\
1994 & 10.715 \\
1995 & 5.500 \\
1996 & 10.512 \\
1997 & \\
500 & \\
1998 & 1.806 \\
1999 & 561.156 \\
2000 & 015 \\
Total & \\
\hline
\end{tabular}

Fuentes: World Trade Monitoring Centre (2016)

* Gruss y Waller (1988). Estos datos integran cueros de P. tajacu y T. pecarí.

Tabla 4. Importaciones de T. pecari con origen en la República Argentina, en cueros por unidad. Corresponden a los países que compraron cueros con origen en Argentina. Período 1980-2000

\begin{tabular}{cc}
\hline Año & Importaciones \\
\hline $1980-1987$ & 0 \\
1988 & 22.521 \\
1989 & 11.652 \\
1990 & 2.000 \\
$1991-2000$ & 0 \\
Total & 36.173 \\
\hline
\end{tabular}

Fuente: World Trade Monitoring Centre (2016)

4 Oliveira LH. 1999. Mensaje de correo electrónico dirigido al autor en su carácter de Autoridad Administrativa CITES de Brasil, con relación a la legislación brasileña sobre comercio de cueros de fauna silvestre y registro de criaderos de T. tajacu y Tpecari. (8/6/99).

5 Taber A. 1990b. Carta dirigida al autor (8/10/90). 
1988 (año en que las exportaciones de Argentina se prohibieron) y 1997, aunque el promedio anual de importaciones con origen en estos países es similar (Perú con 42.909 de promedio aventaja a la Argentina en menos de 3.000 cueros); el promedio anual de exportaciones está ampliamente a favor de Argentina 46.687 vs. 24.651 de Perú (Tabla 3). Esta diferencia se explica en que Perú no reportó exportaciones al WCMC entre 1991 y 1998 años de alta demanda en el mercado internacional.

Considerando el comercio de T. pecari entre 1988 y 1997, las importaciones con origen en Perú (119.210 cueros) superan ampliamente a las de origen argentino (36.173 cueros) debido a que el pecarí labiado es más abundante en aquel país (Tabla 4) (Alfaro Lozano, 19976).

Las exportaciones argentinas de rosillo y majano entre 1975 y 1984, tuvieron un promedio anual de 32.153 cueros (Gruss y Waller 1988). En el bienio 1988-1989, Argentina reportó a CITES la exportación de 358.173 cueros de ambas especies, es decir un comercio superior al registrado durante un período de 10 años antes de la prohibición de exportar.

Resulta llamativo el volumen de las operaciones comerciales de Argentina, teniendo en cuenta que este país prohibió las exportaciones y comercio interno de cueros de pecarí desde febrero de 1988 (República Argentina 1988). Si a esto se agrega que las exportaciones de los países limítrofes estaban prohibidas desde antes de esa fecha, se deduce que Argentina exportaba cueros de países vecinos, lo que resalta en las exportaciones récord de 1988 y 1989. En un análisis comparativo del comercio de cueros de pecaríes entre Argentina, Bolivia, Brasil y Perú durante el período 1950-1990, Bodmer et al. (1993) establecen que "aunque un gran número de cueros fue exportado recientemente por Argentina, es probable que más de la mitad tuvieran origen en Bolivia y Paraguay".

Una situación parecida ocurría en Perú en 1997: el Departamento Madre de Dios no habilitó el comercio de cueros de pecaríes por no contar con estudios científicos que respalden su sostenibilidad, sin embargo, los cueros se dirigieron a Bolivia (García com. pers.). En diciembre de 1997, se observó en la Feria del Barrio Lindo, principal mercado popular de Santa Cruz de la Sierra (Bolivia), la venta de diversos artículos de cuero de pecarí, además de yacaré (Caiman sp.) y carpincho (Hydrochaeris hydrochaeris) entre otras especies.

\section{El Comercio de cueros de pecaríes y la aplicación de CITES}

Durante la $8^{\circ}$ Conferencia de las Partes, CITES expresó su preocupación sobre las especies incluidas en el Apéndice II con volumen de comercio significativo, porque algunos estados miembros tenían problemas para implementar el Artículo IV inc. 2 (a) y 3 de la Convención. En consecuencia, se indicaron acciones primarias (a ser implementadas en 90 días de plazo por los estados miembro notificados) y recomendaciones secundarias (a ser implementadas en el plazo de un año) en relación con las especies involucradas (CITES 1992).

Las recomendaciones primarias pueden incluir medidas administrativas, cuotas de exportación o restricciones temporarias a las exportaciones. Las secundarias, pueden incluir procedimientos administrativos, estudios de campo y la evaluación de amenazas a las poblaciones animales incluyendo el comercio ilegal y la destrucción del hábitat.

Durante la $9^{\circ}$ conferencia de las partes se hicieron recomendaciones secundarias a Bolivia sobre el comercio del rosillo y del majano (CITES 1994a). En la misma reunión, CITES definió como objetivo de mediano plazo el desarrollo de estudios biológicos y de planes de manejo para los pecaríes (CITES 1994b).

Durante la $10^{\circ}$ conferencia de las partes se indicó que Bolivia y Perú se encontraban desarrollando estudios de campo sobre las especies de pecarí (CITES 1997) en concordancia con la implementación de la resolución Conf. 8.9. (CITES 1992).

Llama la atención que en relación con el artículo IV de la Convención, Argentina no haya recibido ninguna recomendación, cuando es sabido que este país sirve de puerto de salida para el comercio ilegal de países vecinos. Esto se explicaría, en que Argentina prohibió la exportación de cueros de pecaríes en 1988 y en 1991, también la importación de cueros de especies que no puedan diferenciarse de las protegi-

Alfaro Lozano L. 1997. Carta dirigida al autor en su carácter de Director General de Áreas Naturales Protegidas y Fauna Silvestre del Instituto Nacional de Recursos Naturales del Perú (Lima, 3/12/97). Carta No 657 97-INRENA-DGANPFS-DCFS. 
das aquí (República Argentina 1991). En 1993, se establecieron prohibiciones para la caza y comercio de los pecaríes (República Argentina 1993).

De todas maneras, la implementación de toda esta legislación no es efectiva. Cabe destacar que Argentina tenía en 1988 más de 3.000 leyes vigentes en relación con la fauna silvestre (Gruss y Waller 1988) a pesar de que el comercio ilegal continúa debido a serios problemas de control y contradicciones en la legislación entre los estados provinciales y entre estos y el Estado Nacional (Reynoso y Bucher 1989). Después de una consulta a especialistas convocados por el Programa de Comercio de la Comisión de Supervivencia de Especies de IUCN (siglas en inglés de la Unión Internacional para la Conservación de la Naturaleza), se determinó que el comercio internacional no representa una amenaza para las poblaciones de P. tajacu y T. pecari (CITES 1999).

\section{Legislación y administración del recurso fauna a nivel provincial y nacional}

El comercio de fauna silvestre en Argentina implica para el comerciante, la obligación de inscribirse en el registro de acopiadores del organismo de aplicación de la Ley Provincial de Fauna, en este caso la SMADS. El comerciante luego indica la cantidad de cueros que quiere comerciar, lo que se acredita en un documento llamado certificado de origen y legítima tenencia. Este instrumento lo habilita para recorrer el territorio provincial hasta reunir la cantidad de cueros establecidos en el mismo, aunque puede ser usado parcialmente, es decir que puede vender una cantidad de cueros menor a la indicada en el documento, quedando vigente el saldo restante.

Para sacar los cueros fuera de la provincia, el empresario debe solicitar una guía de tránsito al organismo de aplicación, para lo que debe presentar el certificado de origen y legítima tenencia. Las autoridades nacionales de fauna silvestre, a su vez autoridad administrativa de CITES en Argentina (SDSPA) entrega certificados CITES de exportación contra la presentación de las guías de tránsito.

La habilitación de las especies que pueden ser cazadas comercialmente, la época de caza, el período de validez de las guías de tránsito y el impuesto interno que paga cada cuero (aforo) para poder ser transportado fuera de la provincia de origen, pueden variar o no todos los años, llegando a ser totalmente contradictorios entre las distintas jurisdicciones provinciales (Reynoso y Bucher 1989).

Esto se debe a que Argentina está organizada bajo un régimen federal, reconociéndose a las provincias como estados independientes con dominio y jurisdicción sobre sus recursos renovables, tal como lo indican los artículos artículos 121 y 124 de la Constitución Nacional (República Argentina 1994). De esta forma cada provincia puede dictar leyes propias en relación con la fauna silvestre, pudiendo adherirse o no a leyes nacionales. A tal punto difieren los intereses entre las provincias y el estado federal, que la Ley Nacional de Fauna Silvestre se aplica únicamente en los territorios nacionales (República Argentina 1981a). Solo una provincia se adhirió a esta Ley sobre un total de veintitrés.

Las diferentes legislaciones provinciales crean ventajas comparativas para los comerciantes por cuanto estos tienden a legalizar el comercio de cueros en la provincia que les signifique menores costos en impuestos internos, además los comerciantes presionan a las provincias para lograr ventajas impositivas y la habilitación de especies para la caza comercial.

Esto pudo comprobarse, debido a que el director de la SMADS inició en 1982 el expediente 14-11626 dirigiéndose al Gobernador de Salta, para que solicite a su par de la provincia limítrofe de Santiago del Estero, que se abstenga de emitir certificados de origen y legítima tenencia de pieles que puedan provenir de Salta, aclarando que ya se había enviado una petición similar en 1978 a esa misma provincia y a la provincia de Formosa (Provincia de Salta 1982).

Entre 1978 y 1982 Salta solo había habilitado la caza deportiva de los pecaríes, cuando en Santiago del Estero era permitida la caza comercial. En el expediente de referencia, se indica que en 1977 Salta legalizó 3.000 cueros de pecarí vs. 53.604 de Santiago del Estero. En 1978 Salta no habilitó la caza comercial de pecaríes pero sí lo hizo Santiago del Estero legalizando 10.739 cueros. De la misma forma, en 1975 Salta emitió una guía de tránsito por 4.800 cueros con origen en Santiago del Estero.

En un estudio sobre el comercio de fauna en Santiago del Estero, Lima (1997) indicó que entre 1984 y 1986, esta provincia emitió guías de tránsito por 76.824 cueros. El autor señala que el comercio 
solo es regulado por la demanda del mercado y que no existen pautas de manejo ni estudios científicos que justifiquen tasas de extracción sostenibles.

El problema de los certificados de origen y legítima tenencia se trató a nivel nacional, durante una de las reuniones del Ente Coordinador Interprovincial para la Fauna (ECIF), que en una de sus actas indica:

Este certificado tiene una validez fija en todo el país y si dentro de ese plazo el acopiador no ha comercializado la totalidad de los cueros que tenía acreditados, puede solicitar la renovación de la documentación sobre el saldo por un plazo similar.

Siendo la legislación sumamente variable, de manera que especies que alguna vez estuvieron habilitadas para la caza comercial, actualmente se encuentran protegidas y en virtud del mecanismo de acreditación antes explicado, existen en todas las jurisdicciones del país, pieles cuyo tráfico se ampara con documentación de varios años atrás y que se renueva periódicamente a solicitud de sus tenedores.

El alto valor económico y el carácter perecedero de los productos mencionados obliga a descartar la posibilidad de los mismos no pudieran ser totalmente comercializados, a pesar del tiempo transcurrido desde el otorgamiento de la documentación original y lleva a presumir que las transacciones existieron sin que se hayan efectuado los descargos correspondientes en la acreditación. Es decir que los cueros amparados originalmente fueron comercializados en el mercado clandestino y con los documentos de vieja data, se ampara en la actualidad nuevos productos provenientes de la caza furtiva (República Argentina 1983).

\section{Administración y control del comercio de cueros a nivel provincial}

La primera ley provincial de fauna se promulgó en 1960 (Ley 3571) la que fue reemplazada por la Ley 5513 en 1979, actualmente vigente (Villanueva 1981). El primer organismo de aplicación se llamaba Dirección General de Recursos Naturales Renovables, que después de varias reestructuraciones administrativas, recibió el nombre de SMADS.

Esta repartición es la encargada de habilitar, previa autorización del poder ejecutivo, las especies, cantidades, zonas y períodos de caza comercial (Art. 15 inc. a). También reglamenta las actividades de caza y pesca comercial y deportiva (Art. 41 inc. e) y ejerce el poder de policía en el ámbito provincial (Art. 41 inc. h).

En 1983, el Gobernador de la provincia fijó nuevas misiones y funciones para la repartición, destacándose entre ellas, el proponer las pautas para la fijación de una política a nivel provincial en materia de recursos naturales renovables, en concordancia con las políticas nacionales (Provincia de Salta 1983).

En relación con este punto, un informe interno del Jefe de Departamento de Protección de la Fauna es por demás elocuente al expresar, que la política de fauna fijada por el director de la repartición no había sido expresamente comunicada; a ello se suma que entre 1949 y 2000 la Dirección de la SMADS estuvo ocupada por 36 directores diferentes, indicando además la falta de coordinación vertical en la adopción y ejecución de las decisiones importantes (Barbarán 2011, Provincia de Salta 1988a).

La capacidad del control del comercio de la SMADS fue muy baja entre 1983 y 1988 de acuerdo con los datos sobre cauciones y decomisos, porque solo se secuestraron 40 cueros de pecaríes (Provincia de Salta 1988a) y 400 en 1989 (obs. pers.). Para incrementar la capacidad de control, SMADS firmó convenios con Gendarmería Nacional y con la Policía de Salta (Provincia de Salta 1991, 1992). Sin embargo, en 1993 la SMADS cerró sus nueve delegaciones forestales en el interior de Salta (Anónimo 1993) resintiendo su poder de fiscalización. Sin embargo, este nunca fue eficiente (Zjaria, com. pers.): entre 1997 y 1998 solo se sancionó a 28 infractores a la ley de fauna.

En la actualidad la repartición cuenta con 10 inspectores y 3 vehículos de reciente adquisición para realizar tareas de control, los que están apostados en las oficinas centrales de la capital de Salta. Debido a la limitada capacidad operativa del Departamento de Fiscalización y Control de la SMADS, los empleados de ese departamento elevaron una propuesta al Gobierno de Salta a principios de abril de 1997 para hacerse cargo de estas tareas en forma privada, sin que prosperara este trámite (Villagrán, com. pers.). 
Tabla 5. Comercio anual de cueros de pecarí por punto de acopio en la Provincia de Salta, período 19731998. Las fuentes (guías de tránsito) no registran diferencias entre el número de cueros correspondientes a P. tajacu y T. pecari

\begin{tabular}{|cccc}
\hline Años o períodos de años & Rivadavia & $\begin{array}{c}\text { Puntos de acopio } \\
\text { Pichanal }\end{array}$ & Sin especificar \\
\hline 1973 & 376 & 0 & 0 \\
\hline 1974 & 1.699 & 0 & 0 \\
1975 & 22.446 & 0 & 0 \\
1976 & 13.790 & 0 & 0 \\
1977 & 0 & 0 & 3.000 \\
\hline $1978-1987$ & 0 & 0 & 0 \\
\hline 1988 & 0 & 4.800 & 0 \\
\hline 1989 & 0 & 3.800 & 0 \\
$1990-1991$ & 0 & 0 & 0 \\
1992 & 0 & 4.000 & 0 \\
\hline $1993-1998$ & 0 & 0 & 0 \\
\hline Total & 38.311 & 12.600 & $3.000^{*}$ \\
\hline$N^{\circ}$ de acopiadores & 2 & 1 & Sin especificar \\
\hline
\end{tabular}

Fuente: DMARN (archivo de guías de tránsito) * Provincia de Salta, 1988b

Instalación de una curtiembre y su efecto en el comercio local

En 1985 una empresa exportadora inició trámites para instalar una curtiembre en el norte de la Provincia de Salta en la localidad de Pichanal, con el fin de curtir principalmente cueros de lagarto tegu (Tupinambis sp.) y de pecaríes, lo que se concretó después de la firma de un convenio con el Gobierno de Salta en 1988 (Provincia de Salta 1988a). En este documento se establecía una cuota de 10.000 cueros de pecaríes totalmente curtidos para la empresa con la condición que abandonen la provincia.

La firma se benefició con una reducción impositiva a fin de promover su instalación, la que generaría puestos de trabajo. También se estableció en el convenio, el compromiso de participar en la implementación de un plan de investigación sobre la conservación y cría en cautiverio de los pecaríes, plan que sería coordinado por la Secretaría de Asuntos Agrarios de Salta a través de la SMADS.

Esta empresa que también poseía curtiembres en Buenos Aires y Castelli (Provincia del Chaco) trabajó entre 1988 y 1992, legalizando el comercio de solo 12.600 cueros en este período, después continuó procesando cueros de tegu, abandonando sus instalaciones en 1994 (Barbarán 1999, Provincia de Salta 1994). La curtiembre solo generó siete puestos de trabajo de acuerdo con el padrón de afiliados de la Federación Argentina de Trabajadores de la Industria del Cuero y Afines, en 1991.

Por otra parte, resulta curioso observar que resulte favorecida con una cuota anual de 10.000 cueros en 1988, después que las exportaciones se suspendieran a principios de ese mismo año, lo que es una evidencia de la contradicción entre la política nacional y provincial sobre fauna silvestre. La instalación de curtiembres en Salta y otras provincias benefició a los exportadores, quienes se aseguraron prácticamente el monopolio de los cueros en las provincias donde se asentaron, lo que les permitía mantener una oferta exportadora estable (Barbarán 2011).

Sin embargo, la política industrial de la Provincia de Salta no era coherente, tal como lo demuestra el convenio firmado entre esta y la empresa en 1988: por un lado, se otorgó a la firma una cuota anual exclusiva para el procesamiento de cueros de pecarí, además de 75.000 cueros de iguana Tupinambis $s p$. $\left(\right.$ Cláusula $1^{\circ}$ ) y desgravaciones impositivas por la industrialización del cuero, que originalmente salía crudo para curtirse en Buenos Aires (todo esto coincidía con un período de alta demanda de cueros en el mercado internacional). Por otra parte, en la cláusula $10^{\circ}$ del convenio, la Provincia se reservó el derecho de habilitar o no la caza comercial de las especies involucradas, haciendo impredecible la continuidad 
de la industria en el largo plazo.

Este hecho permite deducir que el objetivo real de la firma no era establecer una curtiembre, sino tener un beneficio financiero debido a la eximición de impuestos y asegurarse una parte importante del acopio de cueros, estableciéndose como industria en un punto clave, más cercano a los sitios de caza del Chaco Salteño Semiárido y a las fronteras con Bolivia y Paraguay (Tabla 5).

Los registros oficiales de exportaciones entre 1988 y 1989, indican que la firma instalada en Pichanal ocupó el segundo lugar en las exportaciones con 65.184 cueros (18.7\% del total de Argentina) compartiendo el mercado con otras 14 empresas. En estos años Alemania representó 48\% del mercado seguido de Estados Unidos de América e Italia; estos tres países absorbieron $90 \%$ del total exportado (República Argentina 1989).

De acuerdo con un funcionario de la SDSPA, las altas exportaciones de Argentina en 1988-1989 y su posterior continuidad, se explican en la necesidad de liquidar las existencias acumuladas antes de la prohibición de su comercio exterior:

...en épocas de alta inflación como 1987 el negocio era comprar cueros, por eso muchos acopiadores tenían grandes cantidades, antes que se prohíban las exportaciones. Posteriormente a la prohibición esos cueros se vendieron a exportadores; además si los cueros están bien almacenados pueden durar muchos años, por lo que el comercio no se detuvo (Porini, com. pers., 1999).

Esta afirmación, es consistente al cambio de moneda: se pagan los cueros con moneda devaluada, para convertir la mercadería en dólares americanos en el momento de exportar (Mares y Ojeda 1984). Sin embargo, la continuidad de las exportaciones hasta el año 2000, de acuerdo con la base de datos de CITES, permite deducir que gran parte de los cueros se obtuvo en fechas posteriores a la prohibición: no tiene racionalidad económica asumir el costo de adquisición de estos bienes antes de 1988, porque se suman costos financieros, de almacenamiento y de conservación de la mercadería para exportarla 13 años después, a lo que se añade el costo de curtido, porque Argentina tiene prohibida la exportación de cueros crudos desde 1976.

\section{Antecedentes sobre la conservación de los pecaríes a nivel provincial}

La Autoridad Administrativa CITES de Argentina preparó un proyecto de investigación sobre cría y conservación de los chanchos del monte, donde participarían las provincias de Chaco, Jujuy, Santiago del Estero y Tucumán y recibiría financiamiento de la Cámara Industrial de Curtidores de Reptiles (García Fernández 1991) el que no llegó a implementarse en Salta.

SMADS posee diez ha cercadas en Finca Las Costas (al oeste de la ciudad de Salta) la que cuenta con instalaciones destinadas a la recuperación de animales silvestres para luego devolverlos a su hábitat natural.

\section{Condición del hábitat de los pecaríes en Salta}

Impacto del pastoreo y la explotación forestal. El hábitat de los pecaríes en la Provincia de Salta ha retrocedido debido a la tala indiscriminada de bosques, los desmontes, el sobrepastoreo y la explotación petrolera. La ocupación humana con actividades ganaderas en el Chaco Semiárido, comenzó sobre el río Juramento entre los siglos XVI y XVII y sobre el río Bermejo en el Departamento Rivadavia a mediados del siglo XIX, incrementándose los asentamientos humanos entre 1862 y 1865 (Saravia Toledo y Del Castillo 1988).

Hacia 1900 ya se habían agotado los pastos en Rivadavia, ubicada sobre la margen sur del río Bermejo, por lo que se organizó en 1902 una expedición al río Pilcomayo en busca de nuevas tierras de pastoreo (Astrada 1906).

Sobre el último cuarto del siglo XX se introdujo el ferrocarril para dar salida a los productos del bosque y se formaron pueblos alrededor de las estaciones de tren, lo que implica más ocupación humana.

Entre las décadas de 1920 y 1930 gracias a la tecnología de construcción de pozos de agua enmarcados en madera, se colonizaron las áreas interfluvio entre los ríos Pilcomayo y Bermejo (Saravia Toledo y Del Castillo 1988). Así, aparece en el Chaco, una red de puestos ganaderos comunicados por senderos que se limpian permanentemente.

La vegetación periférica a los puestos ganaderos es denudada por el sobrepastoreo. Los grandes árboles 
huecos que constituyen refugios para los pecaríes se retiran para aprovechar la leña o fabricar carbón.

Los desmontes en la Provincia de Salta se concentran de Norte a Sur en el piedemonte occidental de las sierras sub-andinas, desde Pocitos a Rosario de la Frontera, abarcando el área de influencia de las isohietas entre 600 y $1.000 \mathrm{~mm}$, lo que permite obtener cultivos de secano (Bianchi y Yañez 1992). Las estadísticas sobre superficies autorizadas de desmonte en la provincia de Salta entre 1962 y 1996 registran en total 1'245.651 ha (Provincia de Salta 1998).

Los departamentos Rivadavia $\left(25.740 \mathrm{~km}^{2}\right)$ y Anta $\left(22.990 \mathrm{~km}^{2}\right)$ son los principales proveedores de cueros silvestres de Salta y registran para el período 1962-1998 una superficie autorizada para desmontar de 23.164 ha y de 437.018 ha respectivamente (Provincia de Salta 1998).

La superficie autorizada para aprovechamiento forestal en el período 1973-1998, fue de 375.560 ha en Rivadavia y de 156.613 ha en Anta, que en este último caso solo contempla el uso de bosques privados (superficie corregida sobre el libro de registro y fichas de aprovechamiento forestal, del archivo de SMADS). Sin embargo, las cifras no son representativas de la realidad debido al bajo poder de control de la SMADS sobre la extracción y el comercio ilegal de productos forestales de las tierras públicas de Salta, como es el caso de los lotes fiscales $\mathrm{N}^{0} 55$ (234.000 ha) y 14 (405.000 ha) del departamento Rivadavia (Barbarán 2011).

Entre 1998 y 2002 la superficie deforestada en los departamentos Anta, San Martín y Rivadavia fue de 194.389 ha, mientras que entre 2002 y 2006 esta superficie se duplicó, alcanzando las 414.934 ha, debido a la expansión del cultivo de soja (Volante et al. 2009). La superficie desmontada en el área de distribución de los pecaríes en la Provincia de Salta, se incrementó continuamente aproximándose a los dos millones de hectáreas, con una de las tasas de deforestación más altas del mundo (Barbarán y Rojas 2015).

Impacto de la exploración petrolera. La explotación petrolera comenzó en Salta hacia 1910; en 1928 la compañía norteamericana Standard Oil, usando equipos livianos, comenzó a abrir picadas de $6 \mathrm{~m}$ de ancho cada $10 \mathrm{~km}$ en el Chaco Semiárido. La exploración se incrementó a partir de 1932, con la actividad de la empresa argentina Yacimientos Petrolíferos Fiscales. Después de la II Guerra Mundial comenzaron a usarse topadoras para abrir las picadas, incrementándose la velocidad del impacto sobre el hábitat, mientras que el uso de explosivos se intensificó a partir de 1950 (Arias, com. pers.)

Las picadas afectan casi toda la superficie del Chaco Semiárido, pueden tener más de $300 \mathrm{~km}$ de largo y un ancho que varía entre 6 y $8 \mathrm{~m}$, facilitando la formación de cárcavas, la instalación de nuevos puestos ganaderos, la explotación forestal y la penetración de cazadores. Esto tiene un impacto altamente negativo sobre las poblaciones de grandes mamíferos entre los que se destacan los pecaríes (Protomastro y Caziani, $\left.\mathrm{s} / \mathrm{fa}^{7}, \mathrm{~s} / \mathrm{fb}^{8}\right)$. Las picadas podrían cubrirse de vegetación rápidamente, pero esto es impedido por el sobrepastoreo.

Un cazador del paraje Las Tortugas ( $24 \mathrm{~km}$ al sur de la localidad de La Unión) indicó que la apertura de picadas "despedaza el monte" y es la principal causa para la disminución de las capturas de chanchos del monte.

En 1992 la Secretaría de Energía de Argentina reglamentó la exploración petrolera en relación con su impacto sobre el medio ambiente, obligando a que las picadas se abran manualmente usando equipo liviano (República Argentina 1992). El cumplimiento de esta resolución es controlado por la Dirección de Minería de la Provincia de Salta.

Debido al retroceso de su hábitat, se pudo comprobar que los pecaríes sobreviven en áreas de difícil acceso para el hombre y el ganado, como es el caso de las masas impenetrables (chaguarales) de Bromelia sp., tusca (Acacia aromo), vinal (Prosopis ruscifolia) y bosques de palo santo (Bulnesia sarmientoi) (Saravia Toledo 1989a, Chebez 1994). Sin embargo, estas especies han podido adaptarse a los cambios en la cobertura vegetal provocados por el sobrepastoreo

7 Protomastro JJ, Caziani SM. s/fa. Evaluación del impacto ambiental de la prospección petrolifera en los bloques: El Caburé, Monte Quemado, Los Horcones y Talavera. Salta: Universidad Nacional de Salta, Consejo Nacional de Investigaciones Científicas y Técnicas (Inédito).

8 Protomastro JJ, Caziani SM s/fb. Impacto ambiental de las actividades de prospección petrolifera. Pozo X-1, SP 10, Línea 44104. Los Tigres, Santiago del Estero. Salta: Universidad Nacional de Salta Consejo Nacional de Investigaciones Científicas y Técnicas (Inédito). 
y la explotación forestal, lo que permite calificar de "regular" la condición del hábitat remanente (Barbarán 2011).

Hábitos alimenticios de los pecaríes. Durante el trabajo de campo realizado en 1998, pobladores indígenas y criollos de Rivadavia, indicaron que los pecaríes (omnívoros) se alimentan de frutos de Zyziphus mistol, cladodios de Opuntia quimilo, raíces de Bulnesia sarmentoi e Ipomea sp., frutos de Acacia aroma, Bromelia serra, B. hyeronymi y Naphalium sp., mientras que Pennisetum frutescens se consume entera. Todas estas especies son de condición creciente y algunas de ellas se comportan como invasoras, salvo Pennisetum que tiene condición decreciente y Naphalium que mantiene su condición sin cambios al ser forrajera de emergencia (Saravia Toledo y Barbarán 2003, Barbarán 2011).

Los géneros Acacia, Opuntia, Bromelia y Zyziphus son citados por Taber et al. (1994) como componentes de la dieta del rosillo y del majano en el Chaco Paraguayo, a los que agrega Prosopis, Cleistocactus, Cereus, Boherhavia y Eriocereus, todos estos géneros salvo el último, están presentes en Rivadavia.

En el alto y bajo Izozog en el Chaco Boliviano, Lama (1999) encontró en el estómago de 22 ejemplares de $P$. tajacu las siguientes especies que también se encuentran en Rivadavia: Capparis retusa, Caesalpinia paraguarensis, Vallesia glabra, Bromelia hieronymi, Castela coccinea, Capparis tweediana, Zizyzphus mistol, Quabentia pflanzii, Sideroxylon obtusifolium, Harrisia pomanensis, Acacia aroma y Monvillea cavendishii. De estas especies, Z. mistol fue el alimento más consumido, representando 20,4\% del peso total de las fibras analizadas.

\section{Discusión}

La cobertura vegetal densa que necesitan los pecaríes, ha sido disminuida por los desmontes, la explotación forestal y el sobrepastoreo, aunque pueden alimentarse y refugiarse en masas cerradas de árboles y arbustos que colonizaron los antiguos pastizales del Chaco. Sin embargo, son especies muy deseadas como fuente de carne por los pobladores locales y sus hábitos gregarios las hacen vulnerables a la cacería.

De acuerdo con los resultados de esta investigación, se deduce que en el Chaco Semiárido el retroceso del hábitat es el principal problema que enfrentan los pecaríes, aunque el comercio del cuero puede ser problemático si el cazador recibe precios altos. Un cazador puede matar varios miembros de una piara en una sola excursión de caza. T. pecari es más escaso que P. tajacu, porque forma tropas más numerosas y enfrentan a sus perseguidores, quienes se aprovechan de ello para cazarlos en cantidad. Teniendo en cuenta que Argentina continuó exportando cueros de pecarí a pesar de haber prohibido las exportaciones en 1988, se deduce que el sistema administrativo-legal de comercio de cueros facilitó la legitimación del tráfico ilegal, debido a las acreditaciones de almacenamiento que obtienen los exportadores gracias a certificados de origen que no son utilizados en su totalidad.

La frecuencia en el cambio de conducción de la SA en los últimos 64 años indica que se cambia de dirección cada año y medio, lo evidencia el carácter político de las designaciones a pesar de que esta agencia tiene un claro perfil técnico, siendo imposible definir estrategias, proyectar metas operativas y cumplir compromisos en el largo plazo.

La pregunta fundamental es, cómo manejar el recurso con medios limitados y una agencia de fauna débil, considerando a la vez la economía de subsistencia de los cazadores y el beneficio económico que produce la actividad agropecuaria tradicional junto con otras actividades económicas de alto impacto para el hábitat de la fauna silvestre.

En consecuencia, el marco de análisis debería considerar el uso sustentable de todo el ecosistema y no solamente sobre las especies de pecarí. Si se pretende solucionar el problema del tráfico ilegal solo aumentando el control del comercio de cueros, esto será inefectivo, porque no tiene ningún impacto sobre la caza de subsistencia, la que sin duda se seguirá practicando (Moyle 1998). Actualmente, los pecaríes se siguen cazando con fines deportivos y de subsistencia, aunque debido a la baja demanda de cueros, estos se desperdician en muchos casos.

La expansión de la frontera agropecuaria en el Bosque de Transición y Selva Tucumano-Boliviana, la degradación del Chaco Occidental por sobrepastoreo y explotación forestal irracional, implica la necesidad de implementar sistemas de producción multiespecíficos, con la desventaja de que estos emprendimientos requieren fuertes inversiones en el corto plazo y dan retorno negativo por casi diez años, lo que implica la necesidad de subsidiar el sistema 
(Bucher et al. 1998). Si bien el sistema recupera la inversión en el largo plazo (a partir del año 13), la productividad por hectárea en las áreas degradadas se elevaría de 5 dólares a 30 dólares aproximadamente (Saravia-Toledo 19979 , 1989b).

El comercio de productos naturales, en este caso cueros de pecarí originados en áreas bajo manejo sostenible, integrado con la producción de otras especies, podría satisfacer la demanda de consumidores con conciencia ambiental, quienes estarían dispuestos a pagar precios diferenciales altos en relación con productos de origen dudoso. Sin embargo, será difícil competir con ellos, por cuanto tienen menores costos al no tributar impuestos, ni contemplar reinversiones en el manejo del ecosistema.

Un ejemplo de uso sostenible, aunque referido a una sola especie, es el Proyecto Elé, el que implementó la cosecha experimental de loros habladores (Amazona aestiva) por parte de comunidades aborígenes del norte Argentino. Se buscaba implementar un modelo sostenible, porque la exportación de loros fue suspendida por Argentina desde 1992 hasta que no se definan sistemas de uso sostenible para la especie (Banchs y Moschione 1996). Este proyecto creó un sistema de comercialización que generó inversiones para la protección del hábitat y una distribución del ingreso más justa para los cazadores, lo que también es necesario en el comercio de cueros de pecarí.

\section{Conclusiones}

El comercio internacional de cueros de pecarí alcanzó su apogeo entre 1988 y 1990, justo después de que se prohibieran las exportaciones, lo que señala la ineficiencia de la legislación argentina para el control del comercio y para la conservación de las especies de pecarí. Actualmente el comercio de cueros de pecarí en Salta, solo abastece esporádicamente al mercado local, reduciéndose a la venta de cueros producida por la caza de subsistencia.

En el nivel institucional, a pesar de que en Salta existen leyes y organismos vinculados con el uso, protección y conservación de los recursos naturales renovables desde 1858, estos recursos se han degradado como si no existieran ni las leyes ni los organismos encargados de hacerlas cumplir.

Es necesario, un programa de fortalecimiento institucional de la SA, que le permita superar sus problemas de liderazgo, recursos humanos y extensión al medio. En consecuencia, los proyectos deberían ser implementados por organizaciones no gubernamentales de probada trayectoria y capacidad técnica, exentas de vaivenes políticos y electorales.

La realidad demuestra que las políticas de conservación basadas en la simple emisión de leyes y en la adhesión a convenios internacionales, representan una forma elegante de eludir la responsabilidad de una verdadera administración de los recursos naturales, mientras se mantiene la retórica del uso sostenible.

\section{Agradecimientos}

A Sonia Zjaria y Eduardo Villagrán (SMADS), Lucy Aquino y Elena Mendoza (CITES Paraguay), Myriam García y Luis Alfaro Lozano (CITES Perú), Claudio Bertonatti (Fundación Vida Silvestre Argentina), Andrew Taber (Wildlife Conservation Society), Patricia Marconi (Administración de Parques Nacionales) y Julio Arias (Dirección de Minería de Salta), por la valiosa información proporcionada y a Erick Elías por su amistad y su tiempo. El Dr. Kurt Benirschke (Universidad de California, USA) contribuyó a mejorar el manuscrito. Esta investigación ha sido parcialmente financiada por el Consejo de Investigaciones de la Universidad Nacional de Salta (Proyecto 602) y el Consejo Nacional de Investigaciones Científicas y Técnicas de Argentina (CONICET-PIA 7158).

\section{Literatura citada}

Anónimo 1993. Eliminaron delegaciones forestales, las guías serán expedidas por Rentas o comunas. El Tribuno (21/9/93). Salta.

Astrada D. 1906. Expedición al Pilcomayo. Buenos Aires: Editorial Robles; $180 \mathrm{pp}$.

Banchs A, Moschione FN. 1996. Plan experimental para el aprovechamiento sustentable del loro hablador Amazona aestiva en el Norte Argentino. II Captura y comercialización de juveniles. Proyecto Elé. Dirección Nacional de Fauna y Flora Silvestres Fundación Vida Silvestre Argentina, CITES; 15 pp.

Barbarán FR. 1999. Comercialización de cueros de pecarí Tayassu

9 Saravia Toledo CJ. 1997. Ecodesarrollo integral biológico, económico y social de Salta Forestal. Informe inédito para la empresa Ecodesarrollo Salta, Salta, Argentina (Inédito). 
$s p$. en la Provincia de Salta, Argentina, período 1973-1997. En: Fang TG, Montenegro OL, Bodmer RE (eds.). Manejo y conservación de fauna silvestre en América Latina. La Paz: Wildlife Conservation Society; 496 pp.

Barbarán FR. 2001. El aborigen del Chaco Salteño: iniciativas de desarrollo. Periodo 1969-1992. San Salvador de Jujuy: Centro de Estudios Indígenas y Coloniales, Facultad de Humanidades y Ciencias Sociales, Universidad Nacional de Jujuy; 116 pp.

Barbarán FR. 2002. Factibilidad de caza de subsistencia, comercial y deportiva en el Chaco Semiárido de la Provincia de Salta, Argentina. Fermentum. (13) 36: 89-119.

Barbarán FR. 2011. Manual de evaluación de sostenibilidad del comercio de fauna: Experiencia en el Chaco Semiárido Argentino. Saarbrücken: Editorial Académica Española; 400 pp.

Barbarán FR, Rojas L, Arias H. 2015. Evaluación de sostenibilidad institucional y social de la expansión de la frontera agropecuaria. Boom sojero, políticas redistributivas y pago por servicios ambientales en el norte de Salta Argentina. Rev Iberoam Econ Ecol. 24: 21-37.

Bianchi AR, Yañez CE. 1992. Las precipitaciones del noroeste Argentino. $2^{\circ}$ ed. Salta: INTA EEA; 280 pp.

Bodmer R, Sowls L, Taber A. 1993. Economic importance and human utilization of peccaries. In: Oliver WLR (ed.). Pigs, peccaries and hippos action plan: Status survey and conservation action plan. Gland: IUCN; pp. 29-36.

Bodmer R, Aquino R, Puertas P, Reyes C, Fang T, Gottdenker N. 1997. Manejo y uso sustentable de pecaries en la Amazonía Peruana. Occassional Paper No 18 de la Comisión de Superviviencia de Especies. Quito: IUCN; Ginebra: CITES. URL disponible en: http://bibliotecavirtual.minam. gob.pe/biam/bitstream/handle/minam/287/BIV00577. pdf?sequence $=1 \&$ is Allowed $=y$

Broad S. 1984. The peccary skin trade. Traffic Bull. 6 (2): 27-8.

Bucher EH. 1980. Fauna silvestre chaqueña, cómo manejarla? Flora, Fauna y Áreas Silvestres. 1(3): 21-4.

Bucher EH, Schofield CJ. 1981. Economic assault on Chagas disease. New Sci. 92 (1277): 321-4.

Bucher EH. 1989. Conservación y desarrollo en el Neotrópico: en búsqueda de alternativas. Vida Silvestre Neotropical 2(1): 3-6.

Bucher EH, Huszar PC, Saravia Toledo C. 1998. Sustainable land use management in the South American Gran Chaco. $A d v$ GeoEcol. 31: 905-10.

Cámara de Comercio e Industria de Salta. 1951. Carpeta No 87. Actas de constitución de la Cámara Gremial de Barraqueros y Curtidurías (10/10/51). Archivos de la Cámara de Comercio e Industria de Salta.

Cámara de Comercio e Industria de Salta. 1972. Carpeta No 87. Actas de la Cámara Gremial de Barraqueros y Curtidurías (29/8/72). Archivos de la Cámara de Comercio e Industria de Salta.

Cámara Mercantil de Avellaneda. 1983. Boletín No 2; 7 pp.

Cámara de Subproductos Ganaderos de la Bolsa de Comercio de Buenos Aires. 1966. Estilos de plaza y embarque que rigen el comercio doméstico. $10^{\mathrm{a}}$ ed. Buenos Aires, $82 \mathrm{pp}$.

Chebez JC. 1994. Los que se van. Especies argentinas en peligro.
Buenos Aires: Editorial Albatros; 420 pp.

CITES Secretariat. 1992. The trade in wild-caught animal specimens. Resolution Conf. 8.9. $8^{\text {th }}$ Meeting of the Conference of the Parties. Kyoto, Japan 2-13 March 1992; 3 pp.

CITES Secretariat 1994a. Interpretation and implementation of the Convention. Significant trade in Appendix II species. Doc. 9.33. 9th Meeting of the Conference of the Parties, Fort Lauderdale, USA, 7-18 November, 1994; 9 pp.

CITES Secretariat 1994b. Strategic plan of the Secretariat. Doc. 9.17. $9^{\text {th }}$ Meeting of the Conference of the Parties, Fort Lauderdale, USA, 7-18 November 1994; 10 pp.

CITES Secretariat 1997. Interpretation and implementation of the Convention. Doc. 10. 55. Significant trade in Appendix II species. $10^{\text {th }}$ Meeting of the Conference of the Parties, Harare, Zimbabwe, 9-20 June 1997; 11 pp.

CITES Secretariat 1999. CITES significant trade review: ( $T$. pecari) and (P. tajacu). CITES Animals Committee, Madagascar; 9 pp.

Flores E. (s/f). CITES en Bolivia. Trabajo elaborado para el diagnóstico de la diversidad biológica en Bolivia. CDC-AID. Centro de Datos Para la Conservación de Bolivia; 7 pp.

Fuyita HO, Calvo JO. 1982. Las exportaciones de productos y subproductos de la fauna silvestre en el quinquenio 1976/1980. Rev Arg Prod An. l (4): 231-51.

Gruss JX, Waller T. 1988. Diagnóstico y recomendaciones sobre la administración de los recursos terrestres en Argentina: la década reciente (un análisis sobre la administración de la fauna terrestre. Buenos Aires: CITES-WWF-TRAFFIC Sudamérica; 182 pp.

Gruss JX. 1991. Estructuras del comercio de fauna autóctona en la República Argentina: 1990 como muestra. Buenos Aires: WWF-TRAFFIC Sudamérica.

Glanz WE. 1991. Mammalian densities at protected versus hunted sites in Central Panama. In: Robinson JG, Redford KH (eds.). Neotropical wildlife use and conservation. Chicago: The University of Chicago Press; pp. 154-62.

Hemley G. 1986. Tracking Argentina's wildlife trade. Traffic USA. 7(1): 1-8.

Lama M. 1999. Análisis de contenidos estomacales de (Tayassu pecari) y (Pecari tajacu) que habitan en las tierras del Alto y Bajo Izozog. En: Proyecto Kaa-Iya 1999. Estudios de investigación y manejo de fauna en el Izozog y Parque Nacional Kaa-Iya. Exposiciones presentadas en el IV Congreso de Manejo de Fauna en Amazonia y Latinoamérica, 4-8 de octubre de 1999, Asunción, Paraguay. Capitanía del Alto y Bajo Izozog, CABI, Fundación Ivi-Iyambae, Proyecto Kaa-Iya; pp. 140-46.

Lima JJ. 1997. Tráfico de fauna silvestre en Santiago del Estero entre 1984 y 1994. Universidad Católica de Santiago del Estero. Nuevas Propuestas. (21): 35-43.

Mares MA, Ojeda RA. 1984. Faunal commercialization and conservation in South America. Bioscience. 34(9): 580-4.

Morello J, Saravia Toledo CJ. 1959a. El bosque chaqueño I. Paisaje primitivo, paisaje natural y paisaje cultural en el oriente de Salta. Rev Agron Noroeste Arg. 3 (1-2): 5-81.

Morello J, Saravia Toledo CJ. 1959b. El bosque chaqueño II. Paisaje primitivo, paisaje natural y paisaje cultural en el oriente de Salta. Rev Agron Noroeste Arg. 3 (1-2): 209-58. 
Moyle B. 1998. The bioeconomics of illegal wildlife harvesting: an outline of the issues. J Internat Wildlife Law Pol. 1 (1): 95-112. URL disponible en: http://www.tandfonline.com/ doi/abs/10.1080/13880299809353885

Ojeda RA, Mares MA. 1984. La degradación de los recursos naturales y la fauna silvestre en Argentina. Interciencia. 9 (1): 21-6. URL disponible en: https://www.researchgate. net/publication/236332835 La degradacion de los recursos_naturales_y_la fauna silvestre en_Argentina

Provincia de Salta. 1982. Dirección General de Recursos Naturales Renovables. Expediente 14-11626. Salta: Secretaría de Medio Ambiente y Desarrollo Sustentable de Salta.

Provincia de Salta. 1983. Ministerio de Economía. Decreto $N^{o}$ 1556. Boletín Oficial de la Provincia de Salta $(15 / 11 / 83)$ : 4809-10.

Provincia de Salta. 1988a. Convenio entre la Provincia de Salta y Tandeter SA. Salta: Archivos de la Secretaría de Medio Ambiente y Desarrollo Sustentable de Salta.

Provincia de Salta. 1988b. Dirección General de Recursos Naturales Renovables. Memorándum no 30/88. Salta: Archivo de la Secretaría de Medio Ambiente y Desarrollo Sustentable de Salta.

Provincia de Salta. 1991. Decreto 788. Convenio entre la Dirección General de Recursos Naturales Renovables y Gendarmería Nacional (11/7/91). Salta: Departamento de Numeración General de Leyes y Decretos, Gobernación de Salta; 4 pp.

Provincia de Salta. 1992. Decreto 1627. Convenio entre la Dirección General de Recursos Naturales Renovables y la Policía de Salta. Boletín Oficial de la Provincia de Salta (17/11/92): 3157-8.

Provincia de Salta. 1994. Dirección General de Recursos Naturales Renovables. Acta de inspección $N^{o} 0067$ a la curtiembre de Luis Tandeter (14/2/94). Salta: Archivos de la Secretaría de Medio Ambiente y Desarrollo Sustentable de Salta.

Provincia de Salta. 1998. Provincia de Salta: el sector forestal en cifras. Salta: Dirección de Medio Ambiente y Recursos Naturales, Programa de Forestación; 11 pp.

Redford KH, Eisemberg JF. 1992. Mammals of the Neotropics. Vol 2. The Southern Cone: Chile, Argentina, Uruguay, Paraguay. London: The University of Chicago Press Books; 460 pp.

República Argentina. 1981. Ley 22.421. Fauna silvestre, conservación, aprovechamiento, caza. Boletín Oficial de la República Argentina (12/3/81). Separata No 209; 23 pp.

República Argentina. 1976. Ministerio de Economía. Resolución $N^{o} 134 / 76$, suspende la exportación de diversos cueros aptos para la peletería $(13 / 5 / 76) ; 1 \mathrm{pp}$.

República Argentina. 1980. Estadística año 1980. Dirección Nacional de Fauna y Flora Silvestres. Anexo 1; 43 pp.

República Argentina. 1981a. Ley 22.421. Fauna silvestre, conservación, aprovechamiento, caza. Boletín Oficial de la República Argentina (12/3/81). Separata No 209; 23 pp.

República Argentina. 1981b. Estadística año 1981. Dirección Nacional de Fauna y Flora Silvestres; 9 pp.

República Argentina. 1982. Estadística año 1982. Dirección Nacional de Fauna y Flora Silvestres. Exportaciones de pieles, cueros, plumas, lanas y pelos, realizadas desde el
1/1/82 hasta el 9/9/82; 4 pp.

República Argentina. 1983a. Dirección Nacional de Fauna Silvestre. Nota 070/83. Acta de reunión del Ente Coordinador Interprovincial para la Fauna. Actas de reunión del 30/3/83; 9 pp.

República Argentina. 1983b. Estadística 1983. Dirección Nacional de Fauna y Flora Silvestres; 5 pp.

República Argentina. 1984. Estadística 1984. Dirección Nacional de Fauna y Flora Silvestres; 5 pp.

República Argentina. 1988. Secretaría de Agricultura Ganadería y Pesca (SAGyP). Resolución 793/87. Anales de Legislación Argentina XLVIII-A: 175 pp.

República Argentina. 1989. Exportaciones de cueros de pecari entre 1988 y 1989. Dirección de Fauna y Flora Silvestres; $6 \mathrm{pp}$.

República Argentina. 1991. Secretaría de Agricultura Ganadería y Pesca (SAGyP). Resolución $n^{\circ}$ 53/91. Boletín Oficial de la República Argentina (1/3/91). Archivos de la Dirección de Información Parlamentaria de la Legislatura de Salta.

República Argentina. 1992. Secretaría de Energía. Resolución 105/92. Boletín Oficial de la República Argentina (18/11/92). Archivos de la Dirección de Información Parlamentaria de la Legislatura de Salta.

República Argentina. 1993. Subsecretaría de Recursos Naturales. Resolución 1/93. Boletín Oficial de la República Argentina (4/2/93). Anales de Legislación Argentina LIII-A; 338 pp.

República Argentina. 1994. Constitución de la Nación Argentina. Sancionada por la Convención Nacional Constituyente el 22 de agosto de 1994. Editorial Plus Ultra.

Reynoso H, Bucher E. 1989. Situación legal de la fauna silvestre en la República Argentina. Amb Rec Nat. 6 (1): 22-32.

Richard E 1992. Aspectos socioeconómicos de una comunidad rural de Santiago del Estero, con especial referencia a la caza de vertebrados. Resúmenes del II Congreso Regional el NOA y su Medio Ambiente: 94. Universidad Nacional de Salta, 2 al 4 de septiembre de 1992.

Robinson JG, Redford KH. 1991a. The use and conservation of wildlife. In: Neotropical wildlife use and conservation. Chicago: The University of Chicago Press; pp. 3-5.

Robinson JG, Redford KH. 1991b. Subsistence and commercial uses of wildlife in Latin America. In: Robinson JG, Redford KH (eds.). Neotropical wildlife use and conservation. The University of Chicago Press; 460 pp.

Robinson JG, Redford KH. 1991c. Sustainable harvest of Neotropical forest mammals. In: Robinson JG, Redford KH. (eds.). Neotropical wildlife use and conservation. Chicago: The University of Chicago Press; 460 pp.

Saravia Toledo C.J. 1989a. Bases para el manejo de la fauna silvestre en el Chaco Semiárido. Actas de las IV Jornadas Técnicas Uso Múltiple del Bosque y Sistemas Agroforestales. El Dorado, Misiones, Argentina. Vol. I: 168-90.

Saravia Toledo CJ. 1989b. Compatibilización de manejo de pastizales, bosque y fauna en los sistemas agrosilvopastoriles del Chaco Semiárido. En: Forrajeras y cultivos adecuados para la región chaqueña semiárida. Santiago: Oficina Regional de la FAO para Latinoamérica y el Caribe; 119 pp.

Saravia Toledo CJ. 1995. El Departamento Rivadavia: estudio de caso. Historia de un desastre ambiental. En: Gobierno de 
la Provincia de Salta. Antecedentes relativos a las tierras públicas del Lote Fiscal 55. Área Pilcomayo, Provincia de Salta. Salta: Gobierno de la Provincia de Salta; 289 pp.

Saravia Toledo CJ, Del Castillo EM. 1988. Micro y macrotecnologías, su impacto en el bosque chaqueño en los últimos cuatro siglos. Actas del VI Congreso Forestal Argentino. Tomo III. Santiago del Estero: Ediciones Gráficas El Liberal; pp. 853-5.

Saravia Toledo CJ, Barbarán FR. 2003. Condición y tendencia de los recursos forrajeros en el Chaco Semiárido: su evolución entre 1920 y 1998 en los lotes fiscales 55 y 14 (Departamento Rivadavia, Provincia de Salta). Actas del I Congreso Nacional Sobre Manejo de Pastizales Naturales. Vol. II. Conferencias y conclusiones. San Cristóbal, Provincia de Santa Fe, 9 al 11 de agosto del 2001.

Sowls L. 1984. The peccaries. Tucson: University of Arizona Press; 312 pp.

Taber A. 1990a. El taguá. Un plan de acción para su conservación en el Paraguay. Wildlife Conservation International; 34 pp.

Taber AB. 1991. The status and conservation of the Chacoan peccary in Paraguay. Oryx. 25(3): 147-55. URL disponible en: https://www.cambridge.org/core/journals/oryx/ article/the-status-and-conservation-of-the-chacoan-peccary-in-paraguay/EBA52C9E364443D67387633ED$\underline{03 \mathrm{D} 5 \mathrm{E} 72}$
Taber AB, Doncaster CP, Neris NN, Colman FH. 1993. Ranging behavior and population dynamics of the chacoan peccary, Catagonus wagneri. J Mammal. 74 (2): 443-54. URL disponible en: https://www.jstor.org/stable/1382401?se$\mathrm{q}=1 \#$ page scan tab contents

Taber AB, Doncaster CP, Neris NN, Colman F. 1994. Ranging behavior and activity patterns of two sympatric peccaries Catagonus wagneri and Tayassu tajacu, in the Paraguayan Chaco. Mammalia. 58 (1): 61-71. URL disponible en: https://www.degruyter.com/view/j/mamm.1994.58. issue-1/mamm.1994.58.1.61/mamm.1994.58.1.61.xml

Vickers WT. 1991. Hunting yields and game composition over ten years in an Amazon Indian territory. In Robinson JG, Redford KH (eds.). Neotropical wildlife use and conservation. Chicago: The University of Chicago Press; 460 pp.

Villanueva GH. 1981. Legislación de Salta sobre recursos naturales renovables. Salta: Dirección General de Recursos Naturales Renovables, Gobierno de la Provincia de Salta.

Volante JN, Paruelo JM, Morales Poclava MC, Vale L. 2009. Dinámica espacial y temporal de la deforestación en la región Chaqueña del Noroeste Argentino en el periodo 1977-2007. Resúmenes del XIII Congreso Forestal Mundial, Buenos Aires, Argentina.

World Conservation Monitoring Centre 2016. CITES trade statistics derived from the WCMC-CITES trade database (19852009). London: World Conservation Monitoring Centre. 